\title{
Endometrial Volume as a Predictor of Endometrial Pathology in Perimenopausal Uterine Bleeding
}

Hanan Nabil[1), Mouatafa Elzayat ${ }^{(1)}$, Mohammed Moustafa ${ }^{(2)}$, Mahmoud Mohamed Abdelrazik ${ }^{(1)}$

(1)Obstetrics \& Gynecology Department, Faculty of Medicine, Mansoura University, Egypt. (2) Resident Obstetrics \&Gynecology, Ministry of Health and Population, Egypt
Corresponding author:

Hanan Nabil

Assistant professor of Obstetrics and Gynecology

Faculty of Medicine, Mansoura University

e-mail: hanannobil00@yahoo.

com

hanannobil75@gmail.com

\section{$\underline{\text { Abstract }}$}

Background: Transvaginal ultrasonography (TVS) imaging is a routine, non-invasive procedure in initial evaluation of patients with abnormal uterine bleeding in perimenopausal age. However, there is no yet a cutoff value to discriminate benign form malignant cases.

Aim of the Work: Is to assess the potential value of endometrial volume measurements by $2 \mathrm{D}$ TVS compared with that of endometrial thickness in prediction of different endometrial pathologies in women with perimenopausal uterine bleeding.

Patients and Methods: Ninety-two perimenopausal women presented with uterine bleeding were enrolled to the study after exclusion of general and local caused of bleeding as polyps and fibroids. TVS (2D) was done to measure endometrial thickness and volume using a specific formula. Endometrial biopsy was taken and the pathological results was correlated with the endometrial thickness and volume.

Results: There was a statistically noticeable difference between benign endometrial pathology compared to endometrial hyperplasia with atypia or endometrial carcinoma as regard age as well as body mass index. There was a high statistically significant difference between patients with benign endometrium pathology and malignant endometrial pathology regarding endometrial thickness and volume. That endometrial volume had a high predictive value as proved by an area under the ROC curve (AUC) of 0.826 . The best cut-off value was an endometrial volume $>11.675 \mathrm{~cm} 3$. While (ROC) curve analysis for differentiation of patients using endometrial volume and endometrial thickness into women with benign endometrial pathology or hyperplasia and those with endometrial carcinoma; Endometrial volume also had a higher predictive value than endometrial thickness as proved by an area under the ROC curve (AUC) of 0.871 . The cut-off value was an endometrial volume $>13.105 \mathrm{~cm} 3$. While using endometrial thickness cut-off value was an endometrial thickness $>$ $14.5 \mathrm{~mm}$.

Conclusion: endometrial volume measured with inexpensive 2D TVS has a higher predictive value than measuring endometrial thickness in correspondence to the pathological results in patients with perimenopausal bleeding.

Keywords: Perimenopausal bleeding, endometrial volume, 2D transvaginal ultrasound. 


\section{INTRODUCTION}

Persistent changes to the bleeding patterns during the perimenopausal period may be dangerous and careful evaluation should be done. (Klein NA, 1998). The increasing prevalence of obesity and metabolic syndromeyielded to higher incidence of endometrial cancer. Between 1992-1994 and 2009-2011, the European age-standardized rates of uterine cancer in the UK have risen by $48 \%$ (CRUK, 2014).

Transvaginal ultrasound (TVS) is an inexpensive, non-invasive way to indirectly visualize the endometrial cavity. Therefore, it is recommended as a first diagnostic tool to assess uterine pathology in any woman presenting with AUB. There is continuing interest in the role of spectral and color Doppler imaging for the endometrium (Kotdawala, et al.2013).

Measuring of the endometrial thickness for determination of the cause of abnormal uterine bleeding in the perimenopausal women is not easy in absence of anatomical lesions. Anovulatory cycles are a common cause, but hyperplasia, submucousmyomas, and carcinoma are of the concern to the patients (Merce, et al. 1991).

Volumes are usually measured by $3 \mathrm{D}$ where data are retrieved and presented in multi-planer display mode which simultaneously displays three perpendicular planes on the screen for the volume calculation which done by built in computer program using VOCAL. The endometrial volume was measured in plane A by delineating the endometrial margin at the endometrial-myometrial interface from the fundus to the internal cervical in a number of parallel slices which are 1-2 mm apart (Elsokkary M, 2016).Endometrial volume also can be measured by $2 \mathrm{D}$ transvaginal sonography with easy and applicable procedure by 2D TVS ellipse help to predict endometrial pathology. The formula for determining the volume of the endometrium by using one diameter and ellipse or three diametrs of the endometrium.

The basic limitation of all imaging techniques has been the diagnosis of cellular changes in the endometrium. As of now the best use of ultrasonography along with saline infusion sonography in pre-menopausal AUB is to rule out organic pathol- ogies such as a fibroid, adenomyosis, polyp etc., It has been proposed to use the 'thick endometrium' as a screening tool to select patients for histological assessment (Tinelli $\mathbf{R}$ et al., 2008).

The cut off value for endometrial thickness is $>12$ $\mathrm{mm}$ is the most common used for screening but its use is not recommended as this has been found to be inaccurate and a blind adherence. In contrast, endometrial thickness $>4 \mathrm{~mm}$ in post-menopausal bleeding has a better predictive value in diagnosis of about $99 \%$ patients with endometrial cancer. However, repeated episode of postmenopausal bleeding with a endometrial thickness $<4 \mathrm{~mm}$, a biopsy is done to exclude that $1 \%$ chance of endometrial cancer (Litta $\mathbf{P}$ et al., 2005).

Endometrial pathology should be evaluated in women with abnormal uterine bleeding that not responding to a course of therapy for three months. (Brand A et al., 2000).

\section{Aim of the Work:}

Is to assess the potential value of endometrial volume measurements by 2 D TVS compared with that of endometrial thickness in prediction of different endometrial pathologies in women with perimenopausal uterine bleeding.

\section{PATIENTS AND METHODS}

A prospective observational study was conducted on perimenopausal women with abnormal uterine bleeding who attended to Obstetrics \& Gynecology department at Mansoura university hospital.

Patients: From August 2017 till August 2018,ninety two patients who were admitted to Obstetrics \& Gynecology department at Mansoura university hospital suffering from perimenopausal uterine bleeding were enrolled into the study. Age ranged from 4555 years with symptoms of abnormal bleeding e.g. heavy menstrual bleeding, intermenstrual bleeding and polymenorrhea within the last six months. General causes of bleeding e.g. liver cell failure, coagulopathy, hereditaryhemorrhagictelengectasia patients were excluded. Moreover; local causes of bleeding e.g. fibroid, polyp and cervical lesion were also excluded as well as patients with history of drug intake like antiplatelets, anticoagulant or recent hormonal contraception. 
Ethical consideration: Study protocol was submitted for approval by IRB.Informed verbal and written consent was obtained from each participant sharing in the study.

Methods: All patients were exposed to the following

- Full history taking, General, abdominal and pelvic examination

2D-TVS measuring endometrial thickness by Sonoace R3medisone Samsung South Korea device) endometrial thickness is measured at its thickest part in the longitudinal plane. The surrounding more echo lucent layer (or "halo") is considered to be the inner myometrium and is not included.

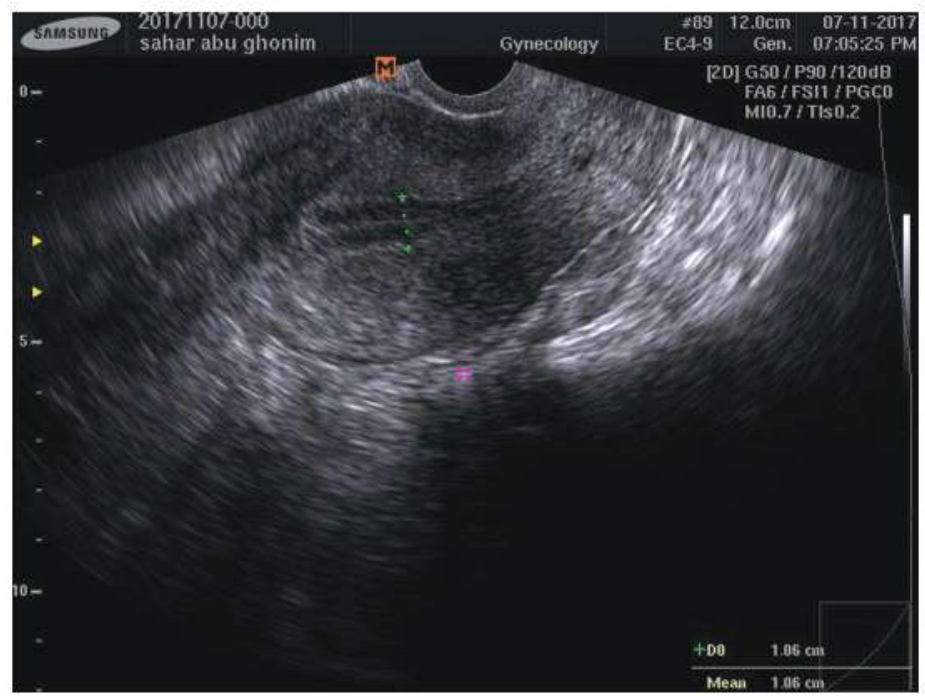

- Fig (1): 2D endometrial thickness by TVS SAMSUNG MEDISONE sonoace R3 South Korea device

- 2D-TVS measuring endometrial volume by the same device. The formula for determining the volume of the endometrium by using one diameter and ellipse reads as follow :

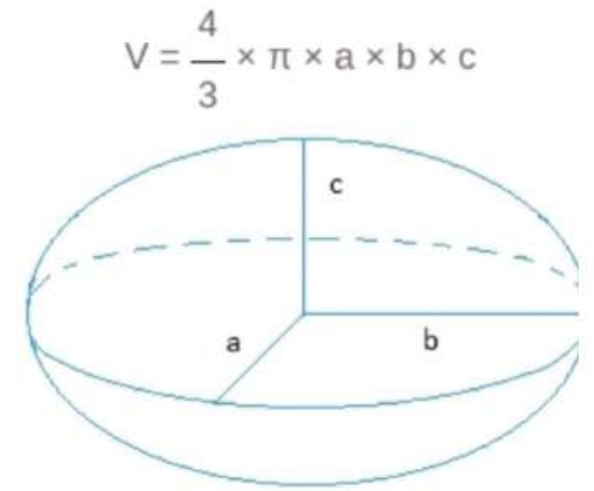

Volume of an ellipsoid

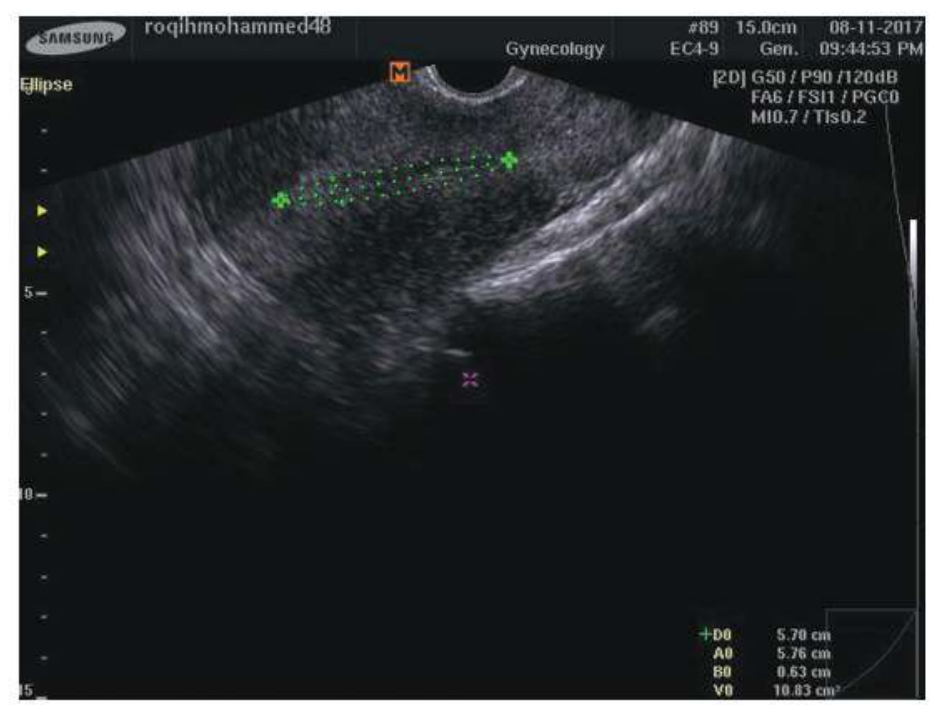

Fig (2): 2D endometrial volume by TVS SAMSUNG MEDISONE sonoace R3 South Korea device

- Patients prepared for dilatation and curettage( one to two days following ultrasonic assessment) using sedating agents e.g. Propofol $2 \%$, Midazolam, Fentanyl.

- Endometrial samples sent to Pathology department at Mansoura university forhistopathological examination.

- Comparison of the endometrial thickness and volume obtained by 2D- TVS with the results of the histopathological examination of endometrial tissue.

\section{Results:}

The mean age of the patients was $50.53 \pm 3.64$ years. About third of them were diabetic patients, half of them were hypertensive, and $2.2 \%$ have had viral hepatitis. 
Table (1): Distribution of the pathological results in women under study:

\begin{tabular}{|l|c|c|}
\hline \multicolumn{1}{|c|}{ Result of pathology } & No & \% \\
\hline Endometrial hyperplasia without atypia & 37 & 40.2 \\
\hline Disordered proliferative endometrium & 23 & 25.0 \\
\hline Endometrial carcinoma & 13 & 14.1 \\
\hline Endometrial hyperplasia with atypia & 7 & 7.6 \\
\hline Proliferative endometrium & 3 & 3.3 \\
\hline picture of irregular endometrial shedding & 1 & 1.1 \\
\hline Scanty endometrial tissue with occasional proliferative glands & 1 & 1.1 \\
\hline Atrophic endometritis & 6 & 6.5 \\
\hline Endometritis & 1 & 1.1 \\
\hline
\end{tabular}

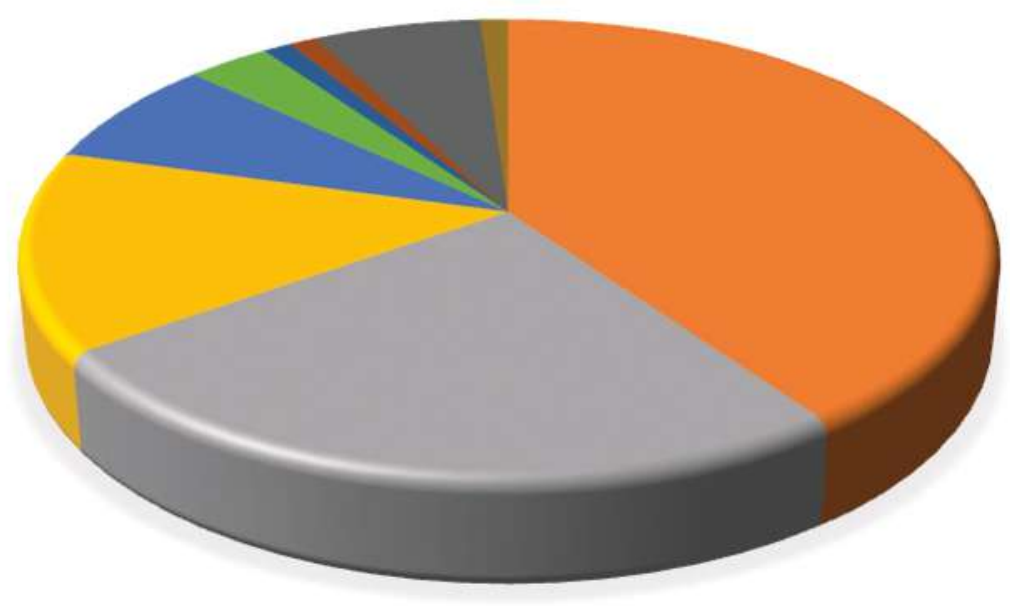

Endometrial hyperplasia without atypia

disordered proliferative endometrium

Endometrial carcinoma

Endometrial hyperplasia with atypia

a proliferative endometrium

a picture of irregular endometrial shedding

Figure (3): Chart for the patients histopathological results

There was a statistically noticeable difference between benign endometrial pathology compared to endometrial hyperplasia with atypia or endometrial carcinoma as regard age [(49.93 \pm 3.58 and $52.70 \pm 3.05)$ respectively], parity $[3.74 \pm 1.48,3.30 \pm 1.59$ respectively $]$ and body mass index $[35.49 \pm 2.34,37.95 \pm$ 1.61respectively] using independent sample t-test. 
Table (3): Endometrial volume and thickness in patients with benign endometrial pathology, endometrial hyperplasia and endometrial carcinoma ranging from the 1stand 3rdquartiles (interquartile range) using Kruskall-Wallis test.

\begin{tabular}{|l|c|c|c|}
\hline & $\mathbf{N}$ & $\begin{array}{c}\text { Endometrial thickness (mm) } \\
\text { [median(range) }\end{array}$ & $\begin{array}{c}\text { Endometrial volume (cm3) } \\
\text { [median(range) }\end{array}$ \\
\hline Benign endometrial pathology & 35 & $9(6-10)$ & $9(7.2-11.7)$ \\
\hline Endometrial hyperplasia & 44 & $10(8-12)$ & $12.2(10.1-18.3)$ \\
\hline Endometrial carcinoma & 13 & $17(13.5-30)$ & $26(16-52.5)$ \\
\hline \multirow{2}{*}{ Kruskall-Wallis test } & $\square 2$ & 23.222 & 26.682 \\
\cline { 2 - 4 } & $\mathbf{P}$ & $<0.001^{*}$ & $<0.001^{*}$ \\
\hline
\end{tabular}

As regarding to endometrial volume and endometrial thickness there was a high statistically significant difference between patients with benign endometrium pathology and malignant endometrial pathology. That endometrial volume had a high predictive value as proved by an area under the ROC curve (AUC) of 0.826 . The best cut-off value was an endometrial volume $>11.675 \mathrm{~cm} 3$. This had a sensitivity of $95 \%$, a specificity of $62.5 \%$, +ve predictive value $41.3 \%$ and -ve predictive value $97.8 \%$ and endometrial thickness cut-off value was an endometrial thickness $>10.5 \mathrm{~mm}$, evidenced by an area under the ROC curve (AUC) of 0.809 This had a sensitivity of $85 \%$, a specificity of $69.4 \%$, +ve predictive value $43.6 \%$ and -ve predictive value $94.3 \%$.

Table (4): ROC curve analysis for differentiation of patient's pathology results into those with benign endometrial results and those with endometrial hyperplasia with atypia or carcinoma using measured endometrial volume

\begin{tabular}{|c|c|}
\hline Variable & Volume \\
\hline Cut off point & 11.675 \\
\hline Area under the curve & 0.826 \\
\hline Sensitivity & $95 \%$ \\
\hline Specificity & $62.5 \%$ \\
\hline Positive predictive value & $41.3 \%$ \\
\hline Negative predictive value & $97.8 \%$ \\
\hline Accuracy & $69.6 \%$ \\
\hline P value & $<0.001 *$ \\
\hline
\end{tabular}

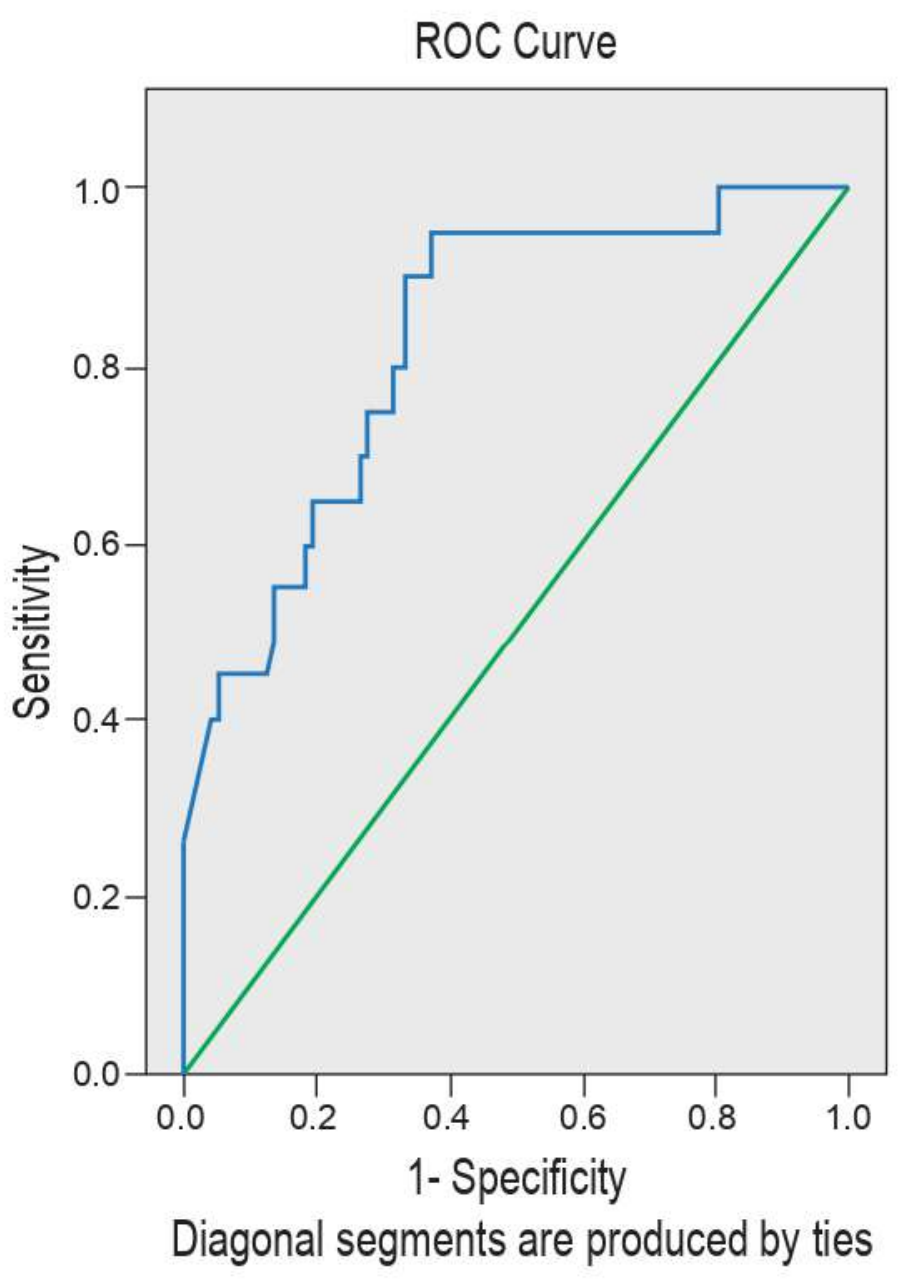

Table (5): ROC curve analysis for differentiation of patient's pathology results into those with benign endometrial pathology and those with endometrial hyperplasia with atypia or carcinoma using endometrial thickness. 


\begin{tabular}{|c|c|}
\hline & Thickness \\
\hline Cut off point & 10.5 \\
\hline Area under the curve & 0.809 \\
\hline Sensitivity & $85 \%$ \\
\hline Specificity & $69.4 \%$ \\
\hline Positive predictive value & $43.6 \%$ \\
\hline Negative predictive value & $94.3 \%$ \\
\hline Accuracy & $72.8 \%$ \\
\hline Pvalue & $<0.001 *$ \\
\hline
\end{tabular}

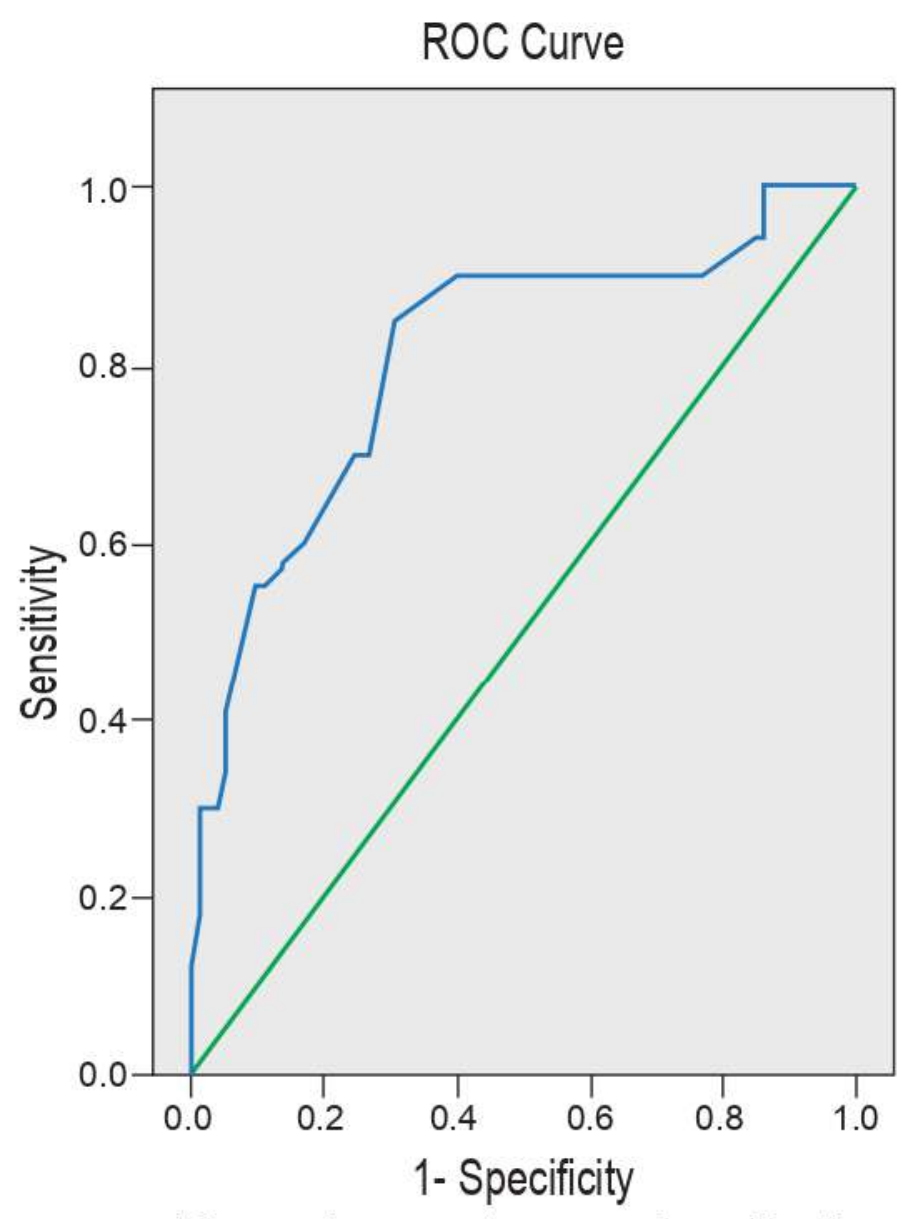

Diagonal segments are produced by ties

The results of the ROC curve analysis for differentiation of patient's pathology into benign endometrial pathology or hyperplasia and endometrial carcinoma using endometrial volume had shown also that endometrial volume had a good predictive value as proved by an area under the ROC curve (AUC) of 0.871 . The best cut-off value was an endometrial volume $>13.105 \mathrm{~cm} 3$. This had a sensitivity of $92.3 \%$, a specificity of $73.4 \%$, Positive predictive value $36.4 \%$ and negative predictive value $98.3 \%$, using endometrial thickness cutoff value was an endometrial thickness $>14.5 \mathrm{~mm}$, proved by an area under the ROC curve (AUC) of 0.867 This had a sensitivity of $76.9 \%$, a specificity of $89.9 \%$, +ve predictive value $55.6 \%$ and -ve predictive value $96 \%$.

Table (6): ROC curve analysis for differentiation of the patient's pathology into benign endometrial pathology or hyperplasia and endometrial carcinoma using endometrial volume at a cut off value of $13.105 \mathrm{~cm}^{3}$.

\begin{tabular}{|c|c|}
\hline & Volume \\
\hline Cut off point & 13.105 \\
\hline Area under the curve & 0.871 \\
\hline Sensitivity & $92.3 \%$ \\
\hline Specificity & $73.4 \%$ \\
\hline Positive predictive value & $36.4 \%$ \\
\hline Negative predictive value & $98.3 \%$ \\
\hline Accuracy & $76.1 \%$ \\
\hline P value & $<0.001^{*}$ \\
\hline
\end{tabular}

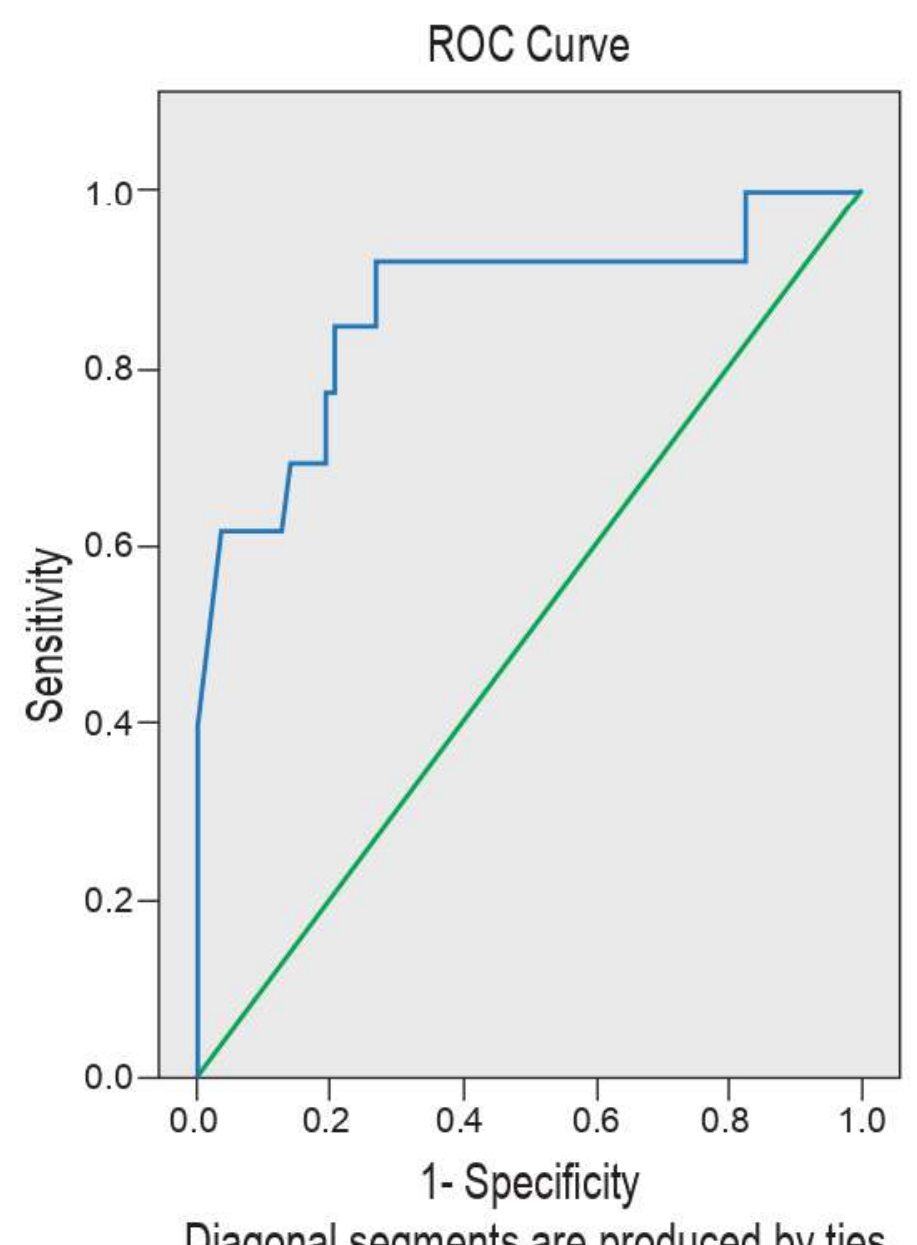

Diagonal segments are produced by ties 
Table (7): ROC curve analysis to differentiation of patient's pathology into benign endometrial pathology or hyperplasia and endometrial carcinoma using endometrial thickness at a cut off value of $14.5 \mathrm{~mm}$

\begin{tabular}{|c|c|}
\hline & Thickness \\
\hline Cut off point & 14.5 \\
\hline Area under the curve & 0.867 \\
\hline Sensitivity & $76.9 \%$ \\
\hline Specificity & $89.9 \%$ \\
\hline Positive predictive value & $55.6 \%$ \\
\hline Negative predictive value & $96 \%$ \\
\hline Accuracy & $88 \%$ \\
\hline Pvalue & $<0.001^{*}$ \\
\hline
\end{tabular}

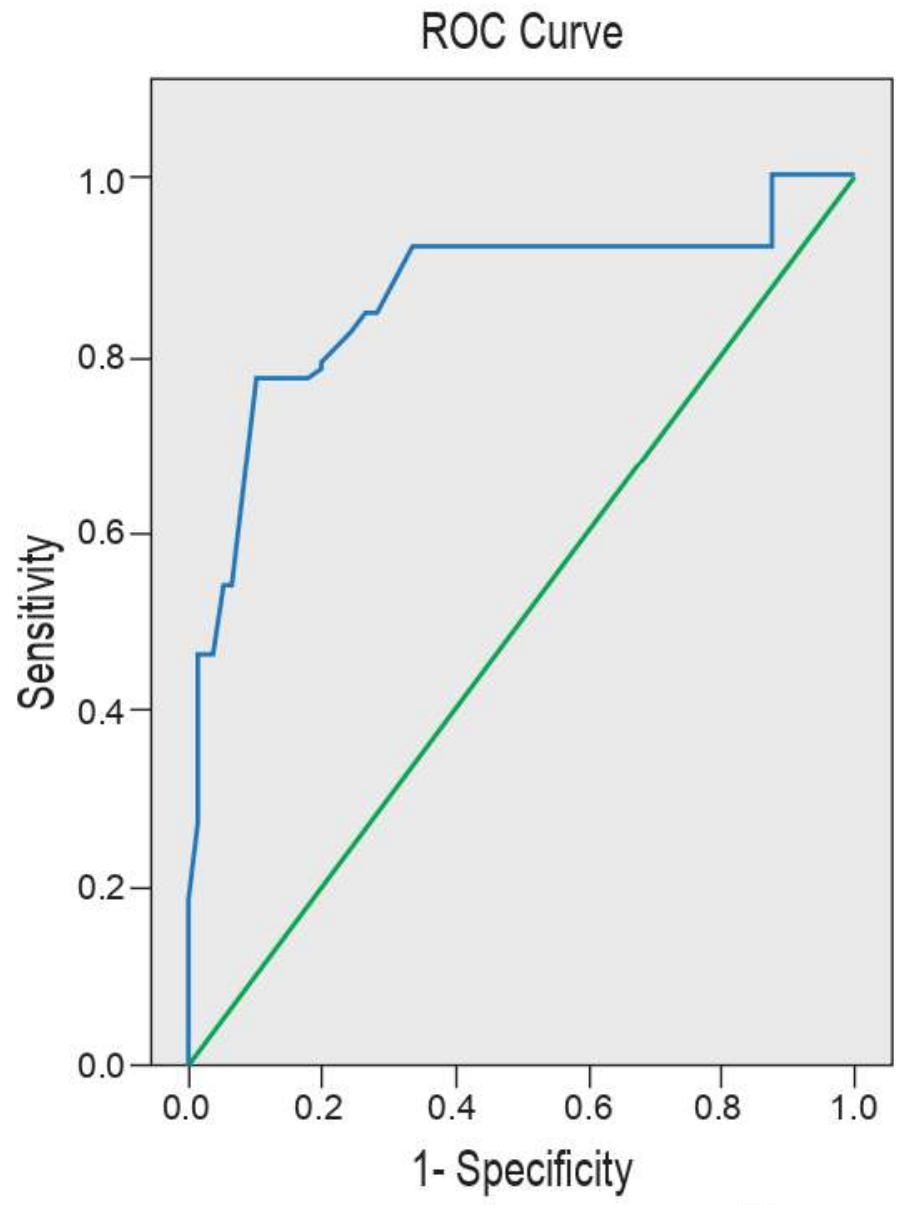

Diagonal segments are produced by ties

\section{Discussion}

Menstrual disorders affect the lifestyle in otherwise healthy women. Once bleeding occurs, investigation should be done to exclude benign and malignant causes (Munro M, 2014).In most studies about $43-66 \%$ of cases with hyperplasia were missed by D\&C when comprising both women with perimenopausal and those with postmenopausal bleeding. (Karampl E et al., 2001).

Three-dimension ultrasound has been used to explore anatomical sections of the uterine cavity; the relations of myomas to the cavity, endometrial polyps can be diagnosed through it and endometrial volume measurement rather than thickness in women with AUB are feasible (Fleischer AC et al., 2003).

The current study aimed at assessment of the potential value of endometrial volume measurements by $2 \mathrm{D}$ transvaginal sonography compared with that of endometrial thickness in foretelling of different endometrial pathologies in women with perimenopausal uterine bleeding. The resultsshowed that there is higher predictive role of endometrial volume in prediction of different endometrial pathologies like hyperplasia or carcinoma that affect women with perimenopausal uterine bleeding and this comes consistent with findings from other studies(M. Odeh et al., 2007, Elsokkary M et al., 2016 and Wael .S. Nossair, 2017).

However, to the best of our knowledge, all studies concerned with assessment endometrial volume were done by $3 \mathrm{D}$ ultrasound machine. However,the financial burden and the limitation of the resources in many areas in the world made the idea of using $2 \mathrm{D}$ and getting accurate results looks glory and reasonable.

The histopathological results in the current studyshowed that $6.5 \%$ of specimen was atrophic endometritis, $25 \%$ was disordered proliferative endometrium, $40.2 \%$ was endometrial hyperplasia without atypia, $7.6 \%$ was with atypiaand $14.1 \%$ was endometrial carcinoma.This is different to another study that showed that myomas found in $32 \%$ of specimens, endometrial hyperplasia in $22 \%$ and endometrial carcinoma in only $4 \%$ of them(Pyari JW, et al., 2006).Low incidence of endometrial atrophy may be explained by the group 
of enrolled patients that usually take hormonal replacement therapy in the perimenopausal period. There is similarity in the prevalence of endometrial carcinoma in the present study $(14.1 \%)$ and that reported in another study (Khare A, 2012).

Regarding to endometrial volume there was a difference between cases with benign endometrial pathology, endometrial hyperplasia and endometrial carcinoma, the medians (IQR) were [9 $(7.2-11.7), 12.2(10.1-18.3)$ and $26(16-52.5)$ cm3 respectively, using Kruskal-Wallis test. Similarly using the same test as regards endometrial thickness there was noticeable difference between them; the medians (IQR) were [9 (6-10), 10 (8$12)$ and $17(13.5-30) \mathrm{mm}$ respectively.

Results were consistent with other study done many years ago, (Kupesic S, et al., 1991), the mean value of the endometrial volume in hyperplasia was $7.82 \pm 7.60 \mathrm{cc}$ and was higher than the volume of patients with polyps (mean $2.63 \pm 2.12$ cc). Correspondingly; in a study done byM. Odeh et al. in 2007the endometrial volume in patients with normal endometrium and pathologic endometrial were $6.87 \pm 6.3 \mathrm{cc}$ and $13.79 \pm 13.2 \mathrm{cc}$ respectively.

Endometrial volume in women with endometrial cancer was $18.1 \mathrm{cc}$ and $11.2 \mathrm{cc}$ in women with hyperplasia; both values were higher than in the normal. Their results showed difference than the current study results that may be explained by the heterogeneity in the group studied and the type of endometrial cancer present.

Discrimination of the results using ROC curve for endometrial volume and thickness into those with benign endometrium and those with endometrial hyperplasia with atypia or carcinoma; endometrial volume had a better predictive value than endometrial thickness as proved by an area under the ROC curve (AUC) of 0.826 . The cut-off value was an endometrial volume $>11.675 \mathrm{~cm} 3$. On the other hand,endometrial thickness cut-off value was $10.5 \mathrm{~mm}$.

While (ROC) curve analysis for differentiation of patients using endometrial volume and endometrial thickness into women with benign endometrial pathology or hyperplasia and those with endometrial carcinoma; Endometrial volume also had a higher predictive value than endometrial thickness as proved by an area under the ROC curve (AUC) of 0.871 . The cut-off value was an endometrial volume $>13.105 \mathrm{~cm} 3$. While using endometrial thickness cut-off value was an endometrial thickness $>14.5 \mathrm{~mm}$.

In another study done to predict the carcinoma of the endometrium in women with postmenopausal bleeding by measuring the endometrial volume through vocal. Patients were classified into two groups of postmenopausal Women with and without bleeding the later was used for control. $50 \%$ of the patients had benign disease, $35 \%$ with atypia and $15 \%$ with cancer in the study group. Whereas in cases with atypia or cancer endometrial thickness was $9.61+/-5.12 \mathrm{~mm}$ but endometrial volume was $3+/-1.1 \mathrm{ml}$, in cases with benign endometrium they were $4.87+/-3.43 \mathrm{~mm}$ and $1.52 \pm 0.82 \mathrm{ml}$, respectively. While in the control group, endometrial volume was $1.15+/-0.14 \mathrm{ml}$ Endometrial volume with cutoff value of $1.35 \mathrm{ml}$ was found to be with higher sensitivity than endometrial thickness in prediction of malignancy (Mansour GM et al., 2007).

Ebrashy et al., 2004; showed that 3Dtransvaginal sonography has higher accuracy than 2dtransvaginal sonography in detection of endometrial pathology. While other studies assessing the value of ultrasound and hysteroscopy in diagnosis of intrauterine lesions showed there is higher sensitivity of combined 2D US and hysteroscopy than 2D US alone in diagnosis of perimenopausal bleeding. (Pasqualotto EB, et al., 2000, Bonnamy et al. 2002, Dery et al. in 2007).

\section{Conclusion}

Our study confirms that endometrial volume is a better diagnostic tool than endometrial thickness in foretelling carcinoma of the endometrium and hyperplasia in women with perimenopausal bleeding. 


\section{Recommendations:}

- Endometrial volume is more sensitive than endometrial thickness for predicting malignancy in perimenopausal women

- The commonest pathology of the endometrium in women with perimenopausal bleeding is endometrial hyperplasia.

- Endometrial volume of $13.105 \mathrm{~cm} 3$ or greater may predict malignancy in women with perimenopausal bleeding.This has a sensitivity of $92.3 \%$, a specificity of $73.4 \%$, Positive predictive value $36.4 \%$ and negative predictive value $98.3 \%$,

- Endometrial thickness cut-off value of benign rather malignant lesion in perimenopuasal women is $>14.5 \mathrm{~mm}$, This has a sensitivity of $76.9 \%$, a specificity of $89.9 \%$, +ve predictive value $55.6 \%$ and -ve predictive value $96 \%$.

\section{Limitation of the study}

This study has some limitations. First, it may be, untilthe date submitting this work, the first observational study to assess the effect of $2 \mathrm{D}$ endometrial volume in foretelling of the endometrial pathology in the Mansoura university hospitals. Second, recruitment of a larger group of patients, multicentric studies may show different relations with different pathologies

\section{References}

1. Bonnamy L, Marret H, Perrotin F, Body G, et al. sonohysterography. A prospective survey of results and complications in 81 patients. Eur $\mathbf{J}$ ObstetGynecolReprodBiol 2002; 102: 42-47.

2. Brand A, Dubuc-Lissoir J, Ehlen T, Plante M. Diagnosis of endometrial cancer in women with abnormal vagi

3. CRUK. Uterine Cancer Incidence Statistics: Uterine cancer incidence trends over time (last reviewed May 2014). Available at: http://www. cancerresearchuk.org/health-professional/cancer- statistics/statistics-by-cancer-type/uterine-cancer/incidence\#ref-2.

4. Dery MC, Van Themsche C, Provencher D, Mes-Masson AM, Asselin E Characterization of EN-1078D, a poorly differentiated human endometrial carcinoma cell line: a novel tool to study endometrial invasion in vitro. ReprodBiolEndocrinol 2007; 5: 38 .

5. Ebrashy A, Momtaz M, Shawky O, Soliman E, AboulMaaty Z Three Dimentional Trans vaginal ultrasound in the assessment of uterine lesions: when do we really need it? Middle East Fertility Society Journal 2004; 9(1): 79-83.

6. Elsokkary M, Shafik A, Nader S () the Role of Endometrial Volume in the Prediction of Endometrial Hyperplasia. Obstet Gynecol Int 2016; J 4(6): 00136.

7. Fleischer AC, ShappellHW Color Doppler sonohysterography of endometrial polyps and sub mucosal fibroids. J Ultrasound Med 2003; 22(6): 601-604.

8. Karampl E, Bourne T, Hurler, Solbakkan H. Istre OTrans vaginal ultra sonography, sonohysterography and operative hysteroscopy for the evaluation of abnormal uterine bleeding. ActaObstetGynecolScand2001; 80(7): 616-622.

9. Khare A Morphological spectrum of endometrium in patients presenting with dysfunctional uterine bleeding. Peoples's Journal of scientific research. 2012; 5(2): 13-16.

10. Klein NA, Soules MR. Endocrine changes of the perimenopause. ClinObstet Gynecol. 1998; 41(4):912-920.

11. Kotdawala P, Kotdawala S, Nagar N. Evaluation of endometrium in peri-menopausal abnormal uterine bleeding. J Mid-life Health 2013; 4:16-21.

12. Kupesic S, KurjakA Color Doppler assessment of the uterine cause's offing fertility. In: Kupesic S \&Kurjak A (Eds). Trans vaginal color Doppler. (2ndedn). The Parthenon Publishing group, USA, 1991; p. 161.

13. Litta P, Merlin F, Saccardi C, Pozzan C, Sacco G, Fracas M, et al. Role of hysteroscopy with endometrial biopsy to rule out endometrial cancer in postmenopausal women with abnormal uterine bleeding. Maturitas 2005; 50:117-23

14. Mansour GM, El-lamie IK, Elkady MA, Elmekkawi SF, Laban M, et al. Endometrial volume as predictor of malignancy in women with 
postmenopausal bleeding. Int $\mathrm{J}$ GynaecolObstet 2007; 99(3): 206- 210.

15. Mercé LT, LópezGarcía G, de la Fuente F. Doppler ultrasound assessment of endometrial pathology. ActaObstetGynecolScand 1991; 70:525-30

16. Munro M. Investigation of Women with Postmenopausal Uterine Bleeding: Clinical Practice Recommendations. Perm J 2014; 18(1): 55-70.

17. Odeh M, Vainerovsky I, Grinin V, Kais M, Ophir E, et al.Three-dimensional endometrial volume and 3-dimensional power Doppler analysis in predicting endometrial carcinoma and hyperplasia. GynecolOncol2007; 106(2): 348-353.

18. Pasqualotto EB, Margossian H, Price LL, Bradley LD Accuracy of preoperative diagnostic tools and outcome of hysteroscopic management of menstrual dysfunction. J Am As-
socGynecolLaparosc 2000; 7(2): 201-209

19. Peddada SD, Laughlin SK, Miner K, et al. Growth of uterine leiomyomata among premenopausal black and white women. ProcNat1AcadSci USA 2008; 105:19887-92.

20. Pyari JW, SachanRekha, Srivastava PK, MadhumatiGoel, Monika Pandey A comparative evaluation of hysteroscopy, trans vaginal ultrasound and history pathological examination in cases of abnormal, uterine bleeding. J ObstetGynecol India 2006; 56(3): 240-243.

21. Tinelli R, Tinelli FG, Cicinelli E, Malvasi A, Tinelli A. The role of hysteroscopy with eye-directed biopsy in postmenopausal women with uterine bleeding and endometrial atrophy. Menopause 2008; 15:737-42.

22. Wael .S. Nossair. The Role of Endometrial Volume in the Prediction of Endometrial Hyperplasia. GynecolReprod Health. 2017; 1(1): 1-5. 